\title{
A ambição de ser o desejo do outro: escritas mestiças de uma família do subúrbio do Rio de Janeiro
}

\section{The ambition of being the desire of the other: mixed writings from a family from the suburban of Rio de Janeiro}

\author{
Andreia Alves Monteiro de Castro* \\ Luciana Pires Alves*
}

\begin{abstract}
RESUMO
O presente artigo procura interpelar as narrativas da experiência mestiça não só como produção de branqueamento, mas também como encenação de um estereótipo. Ambos encarnados na vivência da nossa família, refletindo tensões, modos e projetos de identidade nacional. A romantização da mestiçagem, lugar de produção, de fundação e de disseminação do desejo sempre insatisfeito de ser outro, marca o jogo de projeções, simulações e dissimulações da narrativa de nossa ascendência. Enquanto pesquisadoras, buscamos desvendar alguns mistérios, preencher lacunas, analisar as tensões dessas histórias que nem sempre contavam os fatos pelo que era falado, mas pelo interdito, não dito, mal dito. Conhecer o processo de formação e de conformação das famílias, muitas das vezes, no leva a conhecer o processo de formação e de conformação da sociedade, do país e do mundo.
\end{abstract}

Palavras-chave: Narrativa. Biografia. Representação. Gênero. Raça.

\begin{abstract}
This article seeks to challenge the narratives of the mestizo experience not only as a production of whitening but also as the staging of a stereotype. Both
\end{abstract}

${ }^{*}$ Universidade do Estado do Rio de Janeiro. Rio de Janeiro, Rio de Janeiro, Brasil. E-mail: andreiaacastro@yahoo.com.br - https://orcid.org/0000-0002-2586-6789 E-mail: lualpires@gmail.com - https://orcid.org/0000-0002-8470-4966 
embodied in the experience of our family, reflecting tensions, modes, and projects of national identity. The romanticization of miscegenation, a place of production, foundation, and dissemination of the ever-dissatisfied desire to be another, marks the game of projections, simulations, and concealments of the narrative of our ancestry. As researchers, we seek to unravel some mysteries, fill in gaps, analyze the tensions of these stories that did not always tell the facts for what was said, but for the interdict, not said, ill-said. Knowing the process of formation and conformation of families, many times does not lead to knowing the process of formation and conformation of society, the country, and the world.

Keywords: Narrative. Biography. Representation. Genre. Race.

\section{Representação e identidade}

Segundo Chartier (1990), o conceito de representação se pauta em duas realidades distintas, mas que se interpenetram. Uma diz respeito às identidades coletivas, aos ritos, aos modos que fundamentam as instituições sociais. A outra se refere à identidade do sujeito, às formas de exibição individual e à avaliação desse indivíduo pelo grupo. Por meio da representação, fundam-se padrões, crenças e valores, muitos deles marcados pela transitoriedade, pela instabilidade, pela fluidez, mas todos relacionados a questões estéticas, morais, religiosas, filosóficas, políticas e econômicas, sustentando relações de poder, de dominação e de resistência. A literatura, os jornais, os documentos oficiais, as histórias de vida e os cultos populares são instrumentos de construção, de interpretação, de disseminação e de questionamento das representações dominantes, obviamente, também projetam, mantêm e subvertem identidades individuais e coletivas. Se representar significa dar visibilidade ao outro, historicamente, também significou silenciar outro. Indivíduos ou grupos dominantes, legitimados por instâncias sociais, como classe, raça e gênero, desqualificam, desautorizam ou inviabilizam discursos das minorias marginalizadas, sobretudo as dissonantes. Considerando os postulados desenvolvidos por Kimbérlé Crenshaw (2012) sobre o conceito interseccionalidade, quanto maior for a confluência entres esses eixos de subordinação, mais fortes serão as forças de silenciamento e de opressão.

O presente artigo procura narrar a cena da experiência mestiça. Buscamos inscrever nossas histórias de vida não só na narrativa da produção do sentimento de nacionalidade, mas também da negação dessa noção de pertencimento. Confronto presente nas entranhas ou nas vísceras de nossa sociedade. Disputa 
que Munanga (2019) denomina como "identidade nacional versus identidade negra”. A romantização da mestiçagem ocuparia o lugar de produção de um etnocídio, de fundador e de disseminador do desejo sempre insatisfeito de ser outro, marcando a alteridade como um constante jogo de projeções, simulações e dissimulações. Nossa dupla ascendência é assinalada pela tentativa pelo desejo de se ajustar aos modelos identitários fornecidos pelos discursos coloniais e nacionais: Maria, mulher preta, que buscou encontrar redenção no casamento com um europeu mais velho, viúvo e com três filhos. Ermelinda, mulher branca que dispunha a si e a sua prole aos apetites do capital, num processo de alteridade denominado por Kiening (2014) como selvagens artificiais.

\section{Corpo, desejo e consumo}

No final século XIX, para estimular o consumo, a publicidade associava a imagem feminina a toda sorte de produtos. Em muitos desses anúncios, é possível perceber a intenção de despertar a atenção e o desejo do leitor através da representação sensual do corpo da mulher tornando igualmente desejável tudo aquilo que com ela se oferecia. O sucesso desta estratégia de venda, como é sabido, foi enorme, e os corpos femininos, até hoje, continuam a ser padronizados, exibidos e ofertados, simbolicamente ou de fato, mesmo após tantas lutas feministas.

$\mathrm{Na}$ esfera privada, o corpo feminino também foi usado como capital simbólico na obtenção na manutenção de status social, no caso de mães, esposas e filhas honradas e descentes; de igual modo para a afirmação da virilidade masculina dos que tinham amantes ou outros tipos de relacionamentos com prostitutas. Nessa equação, a beleza do corpo feminino também sempre teve peso. O marido ou amante, que possuía uma mulher admirada e, sobretudo, desejada, desfrutava de um maior prestígio social.

No Brasil, o longo sistema colonial escravocrata parece ter retomado e particularizado estas questões. Sob intensa dominação masculina, o corpo da mulher, principalmente as de pele mais escura, estava realmente submetido aos interesses e vontades dos homens dominantes. O corpo das índias e das negras era entendido como fonte inesgotável e desimpedida de prazer, de trabalho e exploração. 
Detalhes da carta de Pero Vaz de Caminha ao rei Dom Manuel, um dos primeiros registros oficiais do Brasil, revelam a visão do europeu em relação à nudez das nativas. Segundo o escriba, a naturalidade e a falta de vergonha das índias, ao exibirem seus corpos nus, originavam a falta de pudor dos que os admiravam:

Ali andavam entre eles três ou quatro moças, bem moças e bem gentis, com cabelos muito pretos, compridos pelas espáduas, e suas vergonhas tão altas, tão cerradinhas e tão limpas das cabeleiras que, de as muito bem olharmos, não tínhamos nenhuma vergonha (...) e certo era tão bem feita, e tão redonda, e sua vergonha (que ela não tinha) tão graciosa, que a muitas mulheres da nossa terra, vendo-lhe tais feições, fizera vergonha, por não terem a sua como ela (CAMINHA, 2020, p. 5).

Entre os estrangeiros aqui chegados nos séculos seguintes, criou-se um consenso não exatamente deliberado, mas que ultrapassava os limites de nacionalidade e de doutrina: parecia que os trópicos colocavam os deveres morais e religiosos em total suspensão. Se as nativas não tinham vergonha ou culpa ao mostrarem seus corpos, os europeus não tinham vergonha ou culpa ao admirá-los e desejá-los. A nudez como reflexo de uma sexualidade extremada também foi afirmada como elemento que aproximava os indígenas dos animais, fundamentando uma desumanização que só favorecia a exploração do colonizador, que os relatos do cronista e historiador Pêro de Magalhães de Gândavo exemplificam de forma contundente:

vivem como brutos animais sem ordem nem concerto de homens, são muito desonestos e dados à sensualidade e entregam-se aos vícios como se neles não houvera razão de humanos, ainda que, todavia sempre têm resguardo os machos e as fêmeas em se ajuntamento, e mostram ter nisto alguma vergonha (GANDÂVO, 2008, p. 68).

Tal como acontecia nos movimentos de caça às bruxas na Europa, no Novo Mundo, as mulheres mais velhas, devido a sua latente posição de liderança, continuavam a ser demonizadas e temidas: 
Todos seguem muito o conselho das velhas, tudo o que elas lhes dizem fazem e têm-no por muito certo: daqui vem muitos moradores não comprarem nenhumas por lhes não fazerem fugir seus escravos (GANDÂAVO, 2008, p. 69).

Essa aproximação do imaginário medieval também se deu no tocante às mulheres indígenas mais jovens. No discurso e nas imagens produzidas pelos viajantes, as nativas eram retratadas como criaturas eroticamente traiçoeiras, capazes de usar a belezas de seus corpos para seduzir os europeus com intuito de atacá-los e até mesmo devorar os mais desavisados.

Devido à massiva substituição de mão de obra escravizada indígena pela africana, consolidada na virada do século XVII, a mesma figuração de mulher eroticamente disponível e altamente astuciosa foi facilmente atribuída também às mulheres negras e difundida tanto nas colônias como na metrópole portuguesa. As africanas e suas descendentes brasileiras, reificadas e exploradas, receberam, de pronto, a imagem de "amantes mais quentes", de mulheres sempre dispostas a realizar todo e qualquer desejo masculino. A representação destas ardentes "morenas", "pardas" ou "mulatas", trazendo à baila toda a carga significativa subjacente a estes termos, contribuiu para a consolidação e a difusão desta visão, base para a estigmatização, a inferiorização e a marginalização social. Fossem cor de jambo, de canela ou de trigo maduro, a menção às diferentes tonalidades de pele resultantes da miscigenação, com frequência, estava aliada à descrição estereotipada do corpo das brasileiras em geral: seios rijos, cintura fina, quadris largos, glúteos avantajados e pernas bem torneadas. Todo este conjunto de atributos determinaria movimentos peculiaridades, apresentados, quase sempre, como gestos e requebros atraentes e lascivos, sobretudo quando cantam e dançam os ritmos populares.

No entanto, visão, audição e tato não se separavam de paladar e olfato no que tange à percepção do corpo feminino. Segundo Alain Corbin (1987), as sutilezas olfativas permitiam uma nova gestão do desejo para os burgueses. Mães, irmãs, esposas e filhas deveriam exalar o delicado perfume das flores, condizente com o recato e com a discrição a elas convenientes. Jardins passam a ser separados das hortas domésticas e perfumes mais artesanais são superados pelas fragrâncias preparadas por perfumistas. Aromas almiscarados ou aqueles que despertavam o apetite, como o de frutas, ervas e temperos, poderiam ser interpretado como eróticas mensagens olfativas, sendo destinados àquelas que queriam despertar a libido e estavam dispostas aos "gozos sensuais" (CORBIN, 1987, p. 239). 
Essa prescrição a respeito de aromas e sabores, para Affonso Romano de Sant'Anna (2011), se concretizaria na distinção entre a "mulher-flor" e a "mulherfruto", divisão criada e exercida pelo e para o controle masculino. Na divisão espacial dos abastados lares brasileiros do Oitocentos, o lugar da mulher branca seria a entrada da casa, decorando, como flor, o jardim, a fachada e os salões; já o da mulata, como fruto, seria os fundos, a cozinha, a horta, o pomar, espaços ligados à alimentação gastronômica e erótica. E é "entre o jardim e a cozinha, que perambulam os fantasmas do poeta amante, que em suas palavras dramatiza os conflitos do homem médio de seu tempo" (SANT'ANNA, 2011, p. 16).

\section{FIGURA 1 - ILUSTRA DO JORNAL O MEQUETREFE}

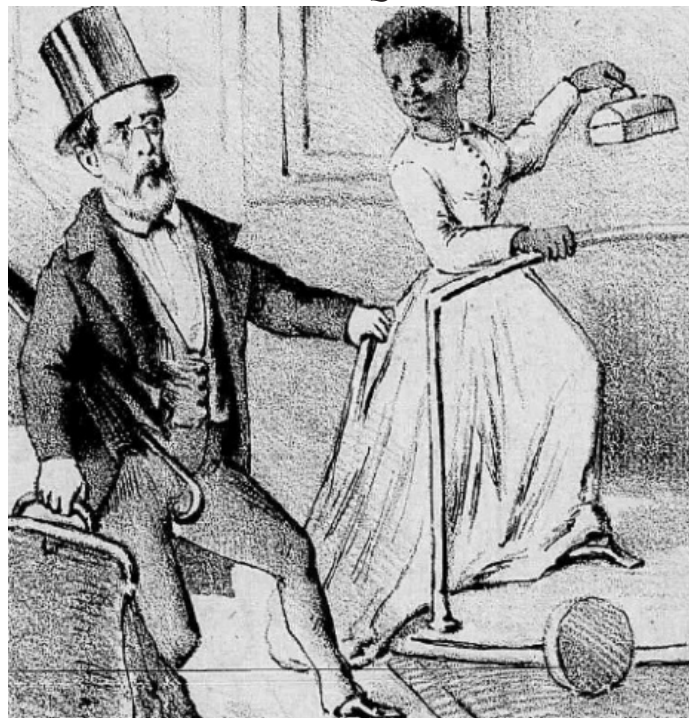

FONTE: O Mequetrefe, 1875.

A mulata é dita imbatível na cozinha e na cama. Cozinhar, amar, duas atividades complementares, se tornam sinônimas e são exploradas em toda sua complexidade e ambiguidade, como vemos na imagem d'O Mequetrefe. A refeição trazida pela mulata ao mesmo tempo indica a sua situação social, mulher pertencente às classes trabalhadoras que prepara seu alimento, e o olhar erótico canibalesco lançando pelo homem branco abastado, cujas posses são representadas pela enorme carteira. Passagens do famoso e controverso livro de Gilberto Freyre, "Casa Grande e Senzala" (1933), revelam como a reificação sexual das mulheres brasileiras obedecia, a partir do imaginário social, um 
espectro cromático: “[...] a mulher morena tem sido a preferida dos portugueses para o amor, pelo menos para o amor físico. [...]. Com relação ao Brasil, que o diga o ditado: "Branca para casar, mulata para f..., negra para trabalhar" (FREYRE, 2005, p. 71-72).

A mulata era "a tal", mas, para poder gozar do prazer de se sentir em uma posição de destaque, era preciso embranquecer. A "mistura", incentivada, legitimada, banalizada, na esfera íntima era a realização de uma falsa promessa de redenção. Já, no projeto de nação, a mestiçagem visava o embranquecimento do povo brasileiro e a destruição de modos plurais de fazer a si sob um signo múltiplo de identidades.

Ideário, desejo e propaganda da política embranquecimento explicitados, postos em cena, na tela A Redenção de Cam, do pintor espanhol Modesto Brocos. O quadro fez sucesso na Europa, acompanhado da legenda: "o negro se torna branco, na terceira geração, por efeito do cruzamento de raças". O poeta Olavo Bilac, sob o pseudônimo de Fantasio, também deixou seu contributo saudando a obra de Brocos na Gazeta de Notícias com os seguintes dizeres: "Vêde a auroracreança como sorri e fulgura, no collo da mulata, - aurora filha do dilúculo, neta da noite... Cham está redimido!..." (FANTASIO, 1895, p. 1).

\section{FIGURA 2 - A REDENÇÃO DE CAM}

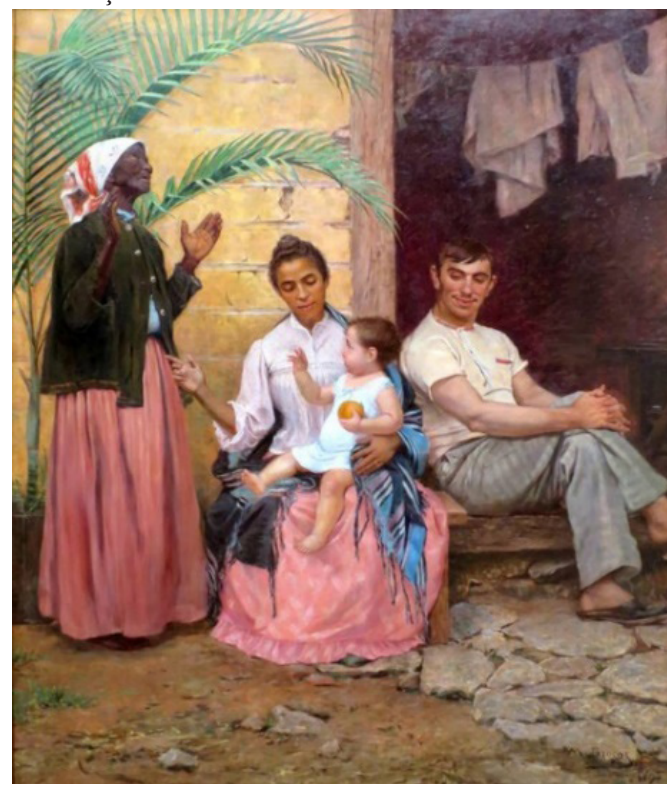

FONTE: Enciclopédia Itaú Cultural, 2020. 
Do mesmo modo que tantas famílias brasileiras, somos atravessadas por esse processo que nomeamos pela ambição de ser "aquilo que o outro deseja". Isso funcionou como motivação para os enlaces e paras tramas familiares. O exame das memórias privadas situa a escrita autobiográfica como rica fonte de análises e de estudos da sociedade brasileira como uma "comunidade imaginada" (ANDERSON, 2008, p. 30). Por acreditarmos que as tramas individuais oferecem fios relevantes para a compreensão coletiva, resolvemos abrir nossos alfarrábios para descrever os percursos de nossas ascendências e ancestralidades.

\section{Ancestralidade e redenção}

O primeiro caminho a ser percorrido é o de nossa bisavó materna: Maria Ramos Gouvea, mulher preta, nascida em 1910, na Serra da Canoa, percorreu os caminhos das Sabinas do Quilombo São José da Serra a Paracambi. Não temos, na memória, relatos de nossa bisavó como quilombola. Tomamos conhecimento desse fato através da certidão de óbito do irmão Benedito sepultado num cemitério do quilombo. $\mathrm{O}$ mesmo silêncio se faz sentir quanto a presença quilombola na história oficial do município de Paracambi. Apesar de possuir um bairro denominado Quilombo, Paracambi é apresentado na historiografia apenas pela ocupação jesuítica, responsável pela fervorosa fé local; pelo domínio colonial, através da fazenda Santa Cruz; pela riqueza hidrográfica, representada pelo Rio dos Macacos; e pela Estrada de Ferro Dom Pedro II, que no período republicano passa a compor a Rede Ferroviária Federal (RFFSA).

Paracambi se modernizou ao receber a Companhia Têxtil Brasil Industrial, que lá se instala visando a exploração das riquezas das águas de seus rios, das madeiras das matas e da força de trabalho da população quilombola que permaneceu no local. Única parcela da população negra que não migrou. Os demais trabalhadores, de posse da liberdade recém garantida, migraram para outras localidades. Esse movimento populacional, inclusive, marcou uma alteração nas atividades econômicas da região. Como afirma Gênesis Torres (2008) numa publicação oficial do Instituto Estadual do Patrimônio Cultural (INEPAC):

Dotada de terras férteis, a região de Paracambi desfrutou, até 1880, de fortes atividades rurais e comerciais, exportando em grande escala cereais, café, farinha, açúcar e aguardente. Com a abolição da escravatura, houve considerável êxodo dos antigos escravos, ocasionando terrível crise econômica (TORRES, 2008. p. 224). 
Ao buscar outros referenciais teóricos, conseguimos estabelecer uma relação entre a presença negra quilombola em Paracambi e a compreensão do florescimento e da prevalência do sagrado de matriz africana em nossa família. Através de Mattos (2006), tomamos conhecimento dos relatos de Toninho Canecão, líder político do Quilombo, que narra a chegada e a partida dos grupos de trabalhadores e trabalhadoras negros da região. Toninho traça rotas muito semelhantes à de nossa família: saindo das fazendas de café, passando por Valença, até chegar às favelas, aos bairros pobres e à Baixada Fluminense.

Nossa família chega a Paracambi vinda de Minas Gerais. Maria Sabina Ramos nasce em 1878, filha da negra escravizada, Sabina das Dores, e de seu senhor branco, António Inácio Seixas. A pequena vem ao mundo após a lei do ventre livre, sendo acolhida pelos saberes e pelas memórias do cativeiro. Sua mãe foi parteira, rezadeira e conhecedora de fazeres que atendiam à primeira infância. Segundo documentos oficiais, residia na Serra da Canoa, em Valença, região pertencente ao importante Quilombo São José da Serra. Maria Sabina se casa, cria seus filhos: Sebastiana, Paulino, Francisco, Benedito, João e Maria. Perde prematuramente alguns e traz tantas outras crianças ao mundo. Nossa bisavó Maria, remanescente quilombola, teve acesso às letras nos descaminhos da precária instrução pública na província do Rio de Janeiro. A região contava com parcas escolas de fazenda. Maria se definia como alguém que apenas sabia ler, jamais escrever. Ainda muito jovem, trabalhou na fábrica de tecidos até o casamento com António. Após o matrimônio passou a morar em São João de Meriti. Além de acolher, cuidar e criar os três filhos do casamento anterior de seu marido, Maria teve mais dez filhos. Desses, apenas seis conheceram a maior idade: Niuza (nossa avó), Neuza, Ari, Aroldo, Amauri e Nilda. Os outros quatro não vingaram, morreram anjinhos, condição muito comum à época.

FIGURA 3 - MARIA E SEUS BISNETOS

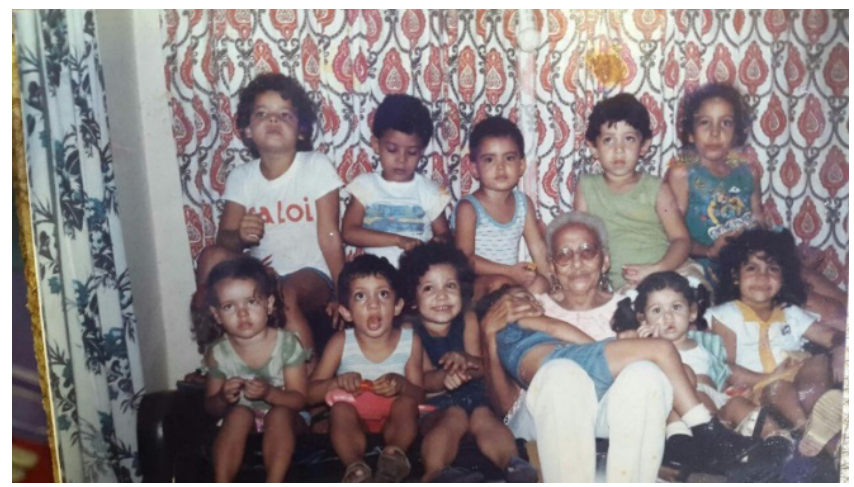

FONTE: acervo das autoras. 
Os frutos de Maria não foram apenas filhos, filhas, netos, netas, bisnetos e bisnetas. Ela trouxe as sementes da cultura e do sagrado quilombola. O terreiro de sua família fez o quilombo ressurgir no entremear das gerações, sendo raiz de resistência cultural contra as investidas de uma identidade nacional forjada a partir da lógica do embranquecimento populacional e apagamento cultural. $\mathrm{O}$ espaço geopolítico negro se manteve vivo nas performances da espiritualidade. $\mathrm{O}$ espaço do terreiro de umbanda é muito semelhante ao espaço do quilombo. $\mathrm{O}$ terreiro reinaugura o quilombo ao resistir ao apagamento identitário, chamado por Munanga (2019) de etnocídio, a via cultural do genocídio.

\section{FIGURA 4 - ESPAÇO SAGRADO DO QUILOMBO SÃO JOSÉ}

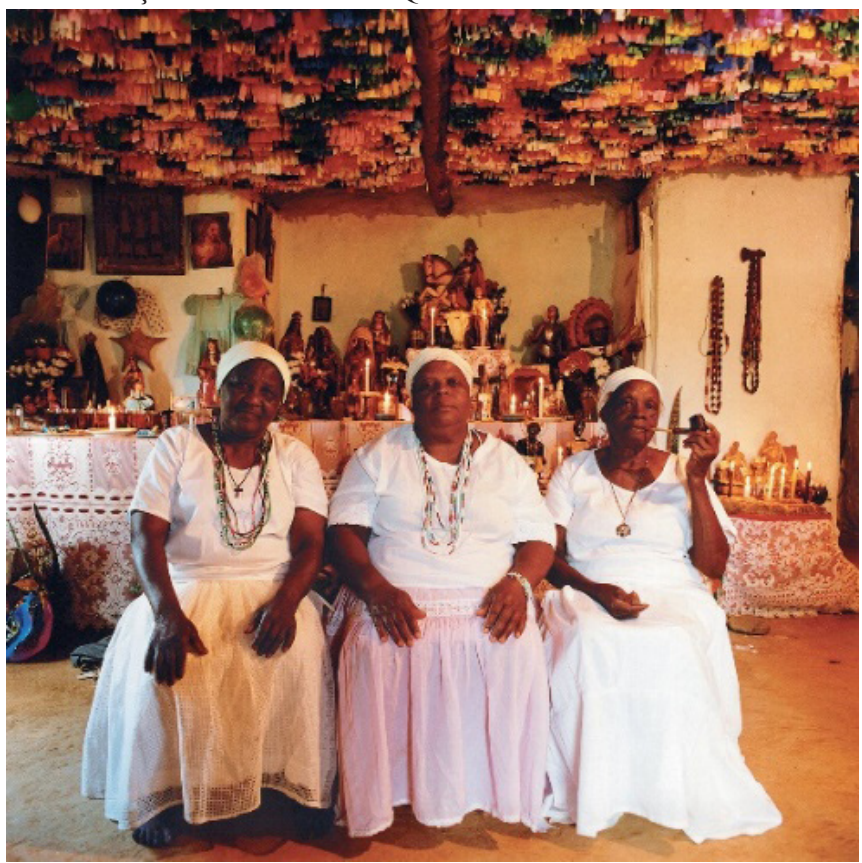

FONTE: Perfil do Facebook, Quilombo São José, 2013. 
FIGURA 5 - COMEMORAÇÃO DE IEMANJÁ NO TERREIRO CABOCLO PENA VERDE

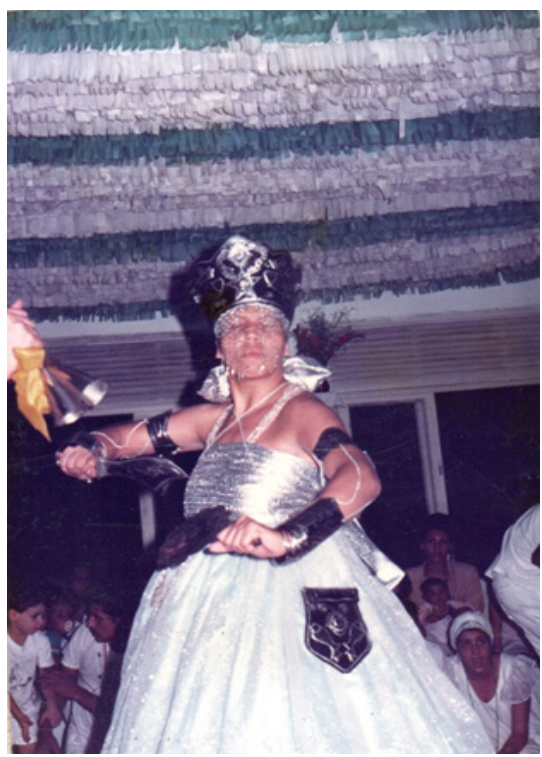

FONTE: acervo das autoras 1987.

Na figura cinco, podemos observar Sandra Maria (nossa mãe), neta de Maria Ramos, no terreiro de nossa família, localizado no subúrbio do Rio de Janeiro. Nosso terreiro, chefiado por Mãe Neusa, era comandado na condição ancestral por Maria Sabina. Vovó Sabina popularizou-se como uma conhecida entidade em vários terreiros de umbanda no Rio de Janeiro. Apesar de toda a estereotipia fixada nas figuras do pai e da mãe pretos, vemos que o imaginário popular cria seus próprios ícones de autoridade no espaço simbólico, reivindicando para si um lugar de representação, memória e devoção. Os pretos velhos, em sua condição ancestral, ganham imagem e valor de culto. Sua presença na esfera do sagrado revela a ineficácia de uma ordem colonial que visava inscrever o outro na ordem fixa da negação, como afirma Bhabha:

Mais uma vez, é o espaço da intervenção que emerge nos interstícios culturais que introduz a invenção criativa dentro da existência. E, uma última vez, há um retorno à encenação da identidade como iteração, a recriação do eu no mundo da viagem, o re-estabelecimento da comunidade fronteiriça da migração (BHABHA, 2001, p. 29). 


\section{A vida como ela é nos jornais: ficções e memórias familiares}

O segundo trajeto pertence a Ermelinda e a sua filha Edwiges, nossa bisavó e tia-avó paternas. As duas protagonizaram escândalos que rechearam de carne e de sangue os folhetins da época. Até a morte de José Gonçalves Mendes, militar, esposo e pai, tanto a mãe como a filha ocupavam com justeza os lugares sociais destinados às mulheres brancas na sociedade carioca do início do século XX. Contudo essa conformidade tinha origem num processo de defloração. O casamento entre José e Ermelinda reparou o "mau passo" dado pelo jovem casal, mas o registro da ação penal jamais se extinguiu, sendo possível consultá-lo, até hoje, no Sistema de Informações do Arquivo Nacional (SIAN):

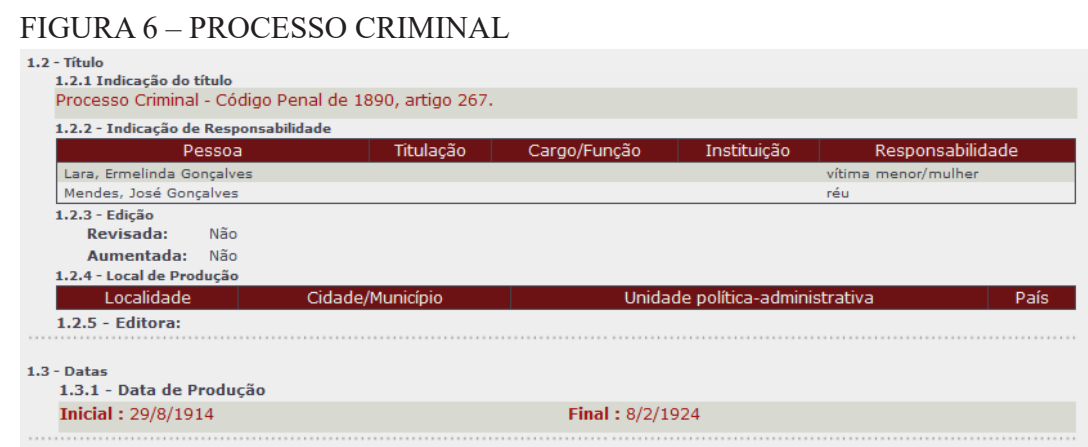

FONTE: BRASIL, 2020.

Casamento de papel passado, certidão de nascimento da primeira e única filha, moradia na vila militar de Marechal Hermes. Família importante e feliz, o tio-avô do rapaz, Francisco José Gonçalves Vieira, desfrutava de posição e prestígio, muitos negócios no Brasil, muitas propriedades em Portugal. A tia, Laura Vieira Alves, viúva e herdeira de um abastado comerciante de tecidos e vinhos do Porto. O primo muito solicito, António Inácio Alves Júnior, capitalista cujo dinheiro fazia girar a economia nos dois países. Mas a morte chega cedo. Um lar malogrado formado por uma jovem e bela mãe e por uma jovem e bela filha, agora, sem arrimo, sem provisão, sem proteção. António Ignácio parecia ser a solução. Braços fraternos, engenho para administrar os negócios e a casa. Ermelinda aceita a corte do rico protetor, pensando que aquele carinho rapidamente faria rimar patrimônio e matrimônio. 
Mais uma gravidez fora do casamento, mais um acerto de contas a fazer. Porém manter conjunção carnal consensual com uma viúva maior de idade não era crime. Glória Emília, "uma interessante menininha", permaneceria fruto ilegítimo deste enlace. Nada de ilegal, mas muito de imoral para aquela sociedade. A história contada pela mãe era a da caridosa perfilhação de uma enjeitada. Outra desamparada para António Ignácio proteger. Status quo quase obedecido.

Contudo, a filha mais velha de Ermelinda não queria continuar a fazer sua figuração muda naquele enleio. Aos quatorze anos, seguindo as pegadas da mãe, foge com um namorado militar. As coisas não saem como o esperado. No ninho de amor, a menina encontra mais de um companheiro. Gritos, choros, violência e violação. $\mathrm{O}$ protetor descobre na Organização Militar o paradeiro do aviador e chega com a polícia para resgatar Edwiges.

Ermelinda, parecendo ignorar a diferença entre sedução e estupro coletivo, pensa em aceitar a reparação prevista no código penal. Casar vítima e agressor parecia ser viável para aquela senhora. Mas não para António Inácio. Ele faz tudo o que pode para afastar a mãe das filhas. Edwiges é internada judicialmente em um colégio de moças. Glória Emília vai morar na casa dos avós paternos. Ermelinda não aceita a situação e procura dar o maior castigo que podia a quem vivia da palavra dada, afiançada pelo nome. Conta a sua versão da história justamente para os jornalistas da família do escritor Nelson Rodrigues que, propositalmente, ignorava os fatos ocorridos para contar não como a vida era, mas como ela podia ser.

Texto e ilustração contavam a história daquelas personagens. A narrativa se construiu através de dois elementos básicos que se superpunham: a história do processo judiciário e a da vida das pessoas envolvidas. Os textos produzidos em uma linguagem simples e hiperbólica, eram publicados com grandes ilustrações, permitindo uma rápida apreensão do assunto abordado. $\mathrm{O}$ aviador sedutor. O comparsa a espera. A fuga com a menina desfalecida e nua nos braços. O inquérito policial. As internações compulsórias. Duas filhas sem mãe. Um salvador transformado em "milhafre" a caçar duas pombinhas. Um senhor que se aproveitava da mãe para estar com a filha. 
FIGURA 7 - MONTAGEM FEITA COM REPORTAGENS DA CRÍTICA

\section{"Se Tivesse Aceilado o lapitalista Como Amanie Não Seria Hoje Desśractada "}

Perdendo o Titulo de Tutora Nata de Sua Filha, a Viuva Empregou-se ComoEnfermeira no Hospital Infantil
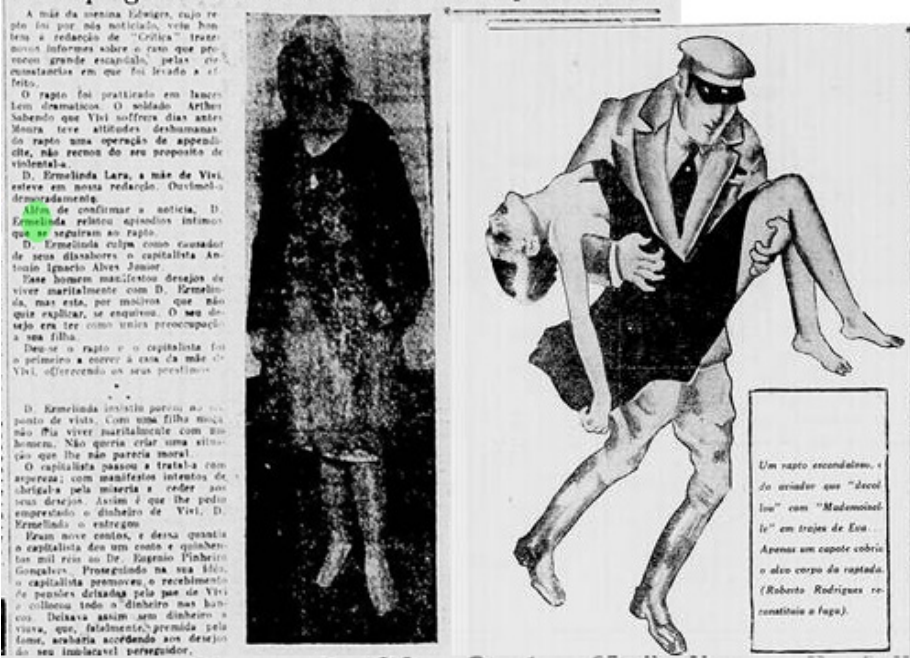

Ol lvidilop Hoing
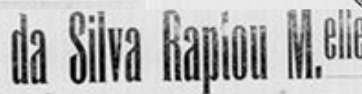

Nilia 8 bosialierilla

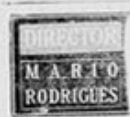

FONTE: Critica, 1929.

No entanto, o negociante, de fato, teve que escolher entre a guarda de sua filhinha, Glória Emília, e o seu bem mais precioso: a honra. Não cedeu a chantagem. Para ele, o nome manchado pela tinta do jornal significou negócios desfeitos. Para Ermelinda e Edwiges, que já não faziam mais parte do grupo das belas, recatadas e do lar, era fama instantânea garantida. Enquanto António Inácio tentava se reerguer. As duas, viciadas em atenção, continuavam povoando as páginas dos periódicos da época, ajudando-os a vender aos leitores uma fuga, mesmo que passageira, da monotonia do cotidiano, uma trégua nas preocupações, um relaxamento das tensões e opressões do dia a dia, uma provinha das sensações interditadas ao "cidadão de bem": 
FIGURA 8 - ALGUNS RECORTES DE JORNAIS COM NOTÍCIAS SOBRE ERMELINDA E EDWIGES

\section{TENTOU SUICIDAR-SE, INGERINDO LYSOL}

Por motivos intinos, hontem, em sua residencia a Eatrada Marechal Rangel n. 299, em Madureira, tentou suicldar-se ingerindo lysol, a menor Edwiges Gonçalves Mendes, de 15 annos de edade, e solteira.

A tresloucada moca fol soccorrida pela Assistencia, no Posto do Meyer. onde fol posta fóra de perigo, retirando-se depols para sua residencta.

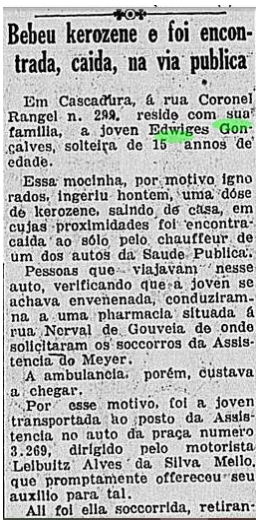

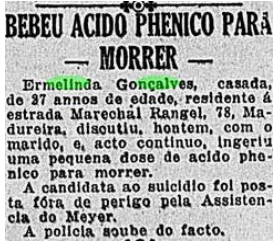

Por ter brigado com o
esposo

FONTE: A Batalha, 1930. Correio da Manhã, 1929. Diário Carioca, 1930.

Depois da desmoralização causada pelas sucessivas reportagens e entrevistas publicadas pela Crítica, António Ignácio nunca mais voltaria a ser quem era. Pequenos negócios no subúrbio do Rio. Aluguéis de imóveis, dinheiro empatado em armazéns e padarias. O sonho de montar a primeira confecção de roupas prontas da capital, nos moldes parisienses, foi por água abaixo. A única herança deste visionário e abortado empreendimento foi conhecer a sua companheira da vida toda. Marie Olga Krug, uma modista franco-lusitana, contratada para trabalhar na confecção, igualmente estrangeira, igualmente só e igualmente com um filho pequeno nos braços. Os quatro se uniram e criaram uma outra família. Novos sonhos, novos dissabores, mas essas já são outras histórias.

Figura 9 - REGISTRO DE PASSAPORTE - LIVRO 238

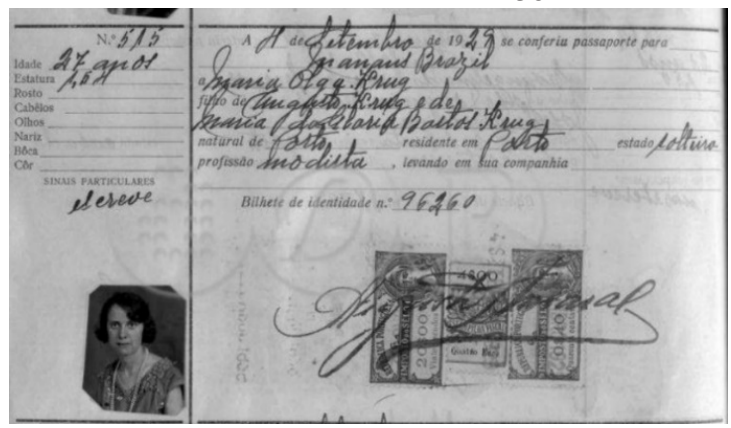

FONTE: Arquivo Distrital do Porto, 2013. 
A redação do jornal também pagou a sua parte nessa dívida de desventuras e desgraças. Segundo a professora e historiadora Magali Gouveia Engel (2005), o periódico de Mário Rodrigues era, ao mesmo tempo, uma folha influente politicamente e "um foliculário de escândalos". Mas de tanto desvelar segredos e ultrajar a vida do "homem comum", também a família Rodrigues provaria do seu amargo veneno. Em 26 de dezembro de 1929, dia de pouca notícia, após a comemoração do Natal, a Crítica saiu com a seguinte manchete: "Entra hoje em juízo nesta capital um rumoroso caso de desquite". O que se seguia ao olho era pura sensação.

FIGURA 10 - RECORTE DA CRITICA

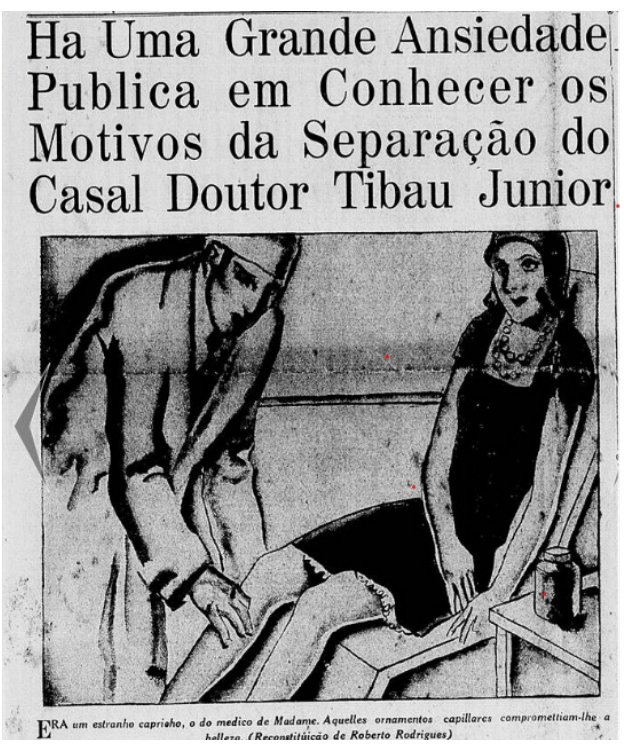

FONTE: Critica,1929.

O jornal acusava Sílvia Tibau, uma bela jornalista e literata de 27 anos, de haver traído o marido, o médico João Tibau Junior. A matéria, escrita com cariz erótico e sensacionalista, transpirando falso moralismo do começo ao fim, revelava detalhes escabrosos, nem todos verídicos, como era de seu feitio. Segundo o redator, "o esculápio" Manuel de Abreu, além de seduzir "madame Tibau", no próprio consultório, teria causado sérios danos à pele "marmórea e sensual" da amante ao tentar extirpar de suas pernas, usando raios X, "algumas expressões capilares pronunciadamente espessas". Entendo que honra se lavava 
com sangue, no mesmo dia em que saiu a reportagem, Sílvia Tibau dirigiu-se, muito bem vestida, à redação da folha, no centro do Rio de Janeiro. Teria pedido para falar com Mário Rodrigues. Como ele não estava, exigiu uma conversa reservada com Roberto, ilustrador e filho do redator. A moça sacou um revólver da bolsa e desferiu em Roberto um tiro à queima-roupa. Profundamente abalado, Mário morreria cerca de dois meses após o ocorrido, em consequência de uma trombose cerebral. Nelson, que na época tinha dezessete anos e era foca no jornal, teria dito que devia muitas de suas histórias e de seu estilo à Critica.

Já Edwiges não mais conseguiu se afastar das luzes da ribalta. António Ignácio, que continuou a ser tutor da moça mesmo quando ela decidiu voltar para o regaço da mãe, conseguiu lhe um bom casamento, mas a tal união não foi duradoura. Em 1942, Edwiges, a moça de nívea pele e olhos verdes, já havia dado lugar a Yara Mendes, a sensual "estrela morena" que combinava o "misticismo afro-brasileiro" e o "ritmo estranho do cantar indígena" em sua "voz bonita", como dizia o anúncio da Rádio Tupi, veiculado no Diário da Noite do dia 26 de dezembro de 1942:

FIGURA 11 - PROPAGANDA DO PROGRAMA LENDA E NARRATIVAS DA RÁDIO TUPI

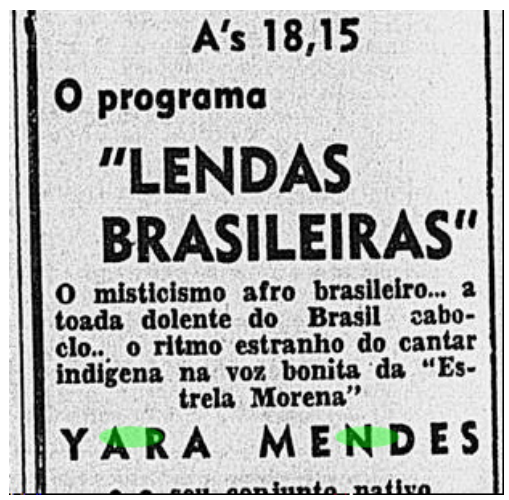

FONTE: Diário da Noite, 1942.

Embora a carreira não tenha sobrevivido à época de ouro, a cantora de rádio e lady crooner do Cassino Atlântico realmente fez sucesso digno de primeira página dos jornais e de capa de revistas na década de 40 do século XX: 
FIGURA 12 - NOTÍCIAS E CAPAS DE REVISTA

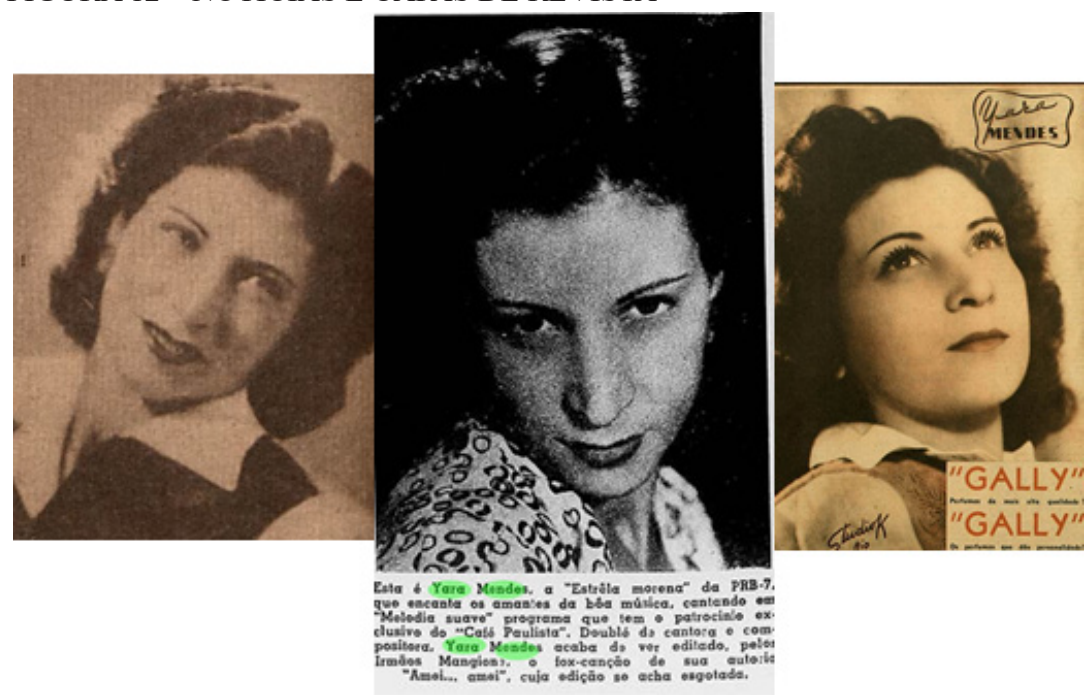

FONTE: O Cruzeiro, 1943. Vida Doméstica, 1943. Vamos Ler, 1943.

Narrar é escovar a história a contrapelo, incluído o discurso oficial. $\mathrm{O}$ apagamento da trajetória transgressora de Edwiges e a invenção de Yara Mendes, estão a par e passo da tentativa de metamorfose do velho mundo no novo mundo. A mestiçagem, abordada apenas pelo viés do processo de embranquecimento, deixa passar ao largo os processos de cópia e de mímica feita do branco. Os europeus, em um processo antropofágico, se alimentavam dos demais grupos raciais. Quando visamos compreender a sociedade brasileira, sob a ótica das comunidades imaginadas, encontramos a retórica do estranho familiar. Semelhante ao que Kiening (2014) afirma sobre a produção simbólica de seres maravilhosos, constituídos através de uma prática canibal, consumidos como souvenir de viagens. O ser prodigioso local passa a ser comercializado através dos contos de um universo de sensações. Situação vivida por Yara Mendes é uma dupla torção dessas narrativas. Mesmo sendo branca e pertencente a uma família oriunda de Vila Real, Portugal, Edwiges assume o nome artístico de Yara, nome de origem tupi que significa Rainha das águas. Assistimos à passagem da alva pombinha à estrela morena Yara Mendes. Ajustada aos holofotes, a jovem Edwiges passar a ser objetificada como mais um dos itens de catálogo do Presente Sensual dos Trópicos. Entre as maravilhas "made in Brazil" teríamos souvenires de diferentes naturezas: humanas, ambientais e culturais. 


\section{Conclusão}

O que podemos encontrar em nossos álbuns familiares, além de comoventes memórias e jocosas brincadeiras? A jornada atenta a nossos alfarrábios nos permitiu perceber o elo entre as memórias particulares e a experiência de tantos. Ao narrar nossas histórias de vida, oferecemos testemunhos históricos e políticos de um tempo, de um grupo e de um território sempre em transformação. Esse "Eu" comum a tantos nos oferece a compreensão do jogo de forças entre as narrativas gerais, que aqui vemos como a tentativa da construção de uma identidade nacional mestiça a exemplo das "Comunidades Imaginadas", de Anderson. Marias, Ermelindas e Yaras viveram o peso das inscrições sociais de seu tempo em seus corpos, cedendo, enfrentando e dissimulando as práticas políticas e discursivas pertencentes às engrenagens de um regime bárbaro capitalista. Nas vivências cotidianas, sentimos o funcionar de nossa sociedade, a exemplo de um lugar que Didi-Huberman (2011, p. 41)chamou de "reino mercantil, prostitucional, da tolerância generalizada". À existência da mulher pesou o casamento com o estrangeiro que representou uma via de acolhimento a população pobre e excedente da Europa. No íntimo, a "Redenção de Cã" camuflou a perpetuação da escravização e o genocídio físico e cultural do povo preto travestida de amor. O feminino fora instrumentalizado pela imprensa nascente, que não se furtou a jogar de forma leviana com os lugares sociais e representações destinados às mulheres.

Nem tudo resultou em escombros, há uma via ética e estética de resistência no sagrado, na arte e no estudo, que compuseram vias de retomadas de si mesmas. A percepção disto permitiu a escrita do presente texto nos moldes do que diz Benjamin (1995, p. 225): "O dom de despertar no passado as centelhas de esperança é privilégio exclusivo do historiador convencido de que também os mortos não estarão em segurança se o inimigo vencer. Esse inimigo não tem cessado de vencer".

O interpelar cuidadoso das histórias de vida, através das fontes documentais e das memórias trazidas de cor, nos possibilitou perceber as misturas e as correlações entre as histórias pessoais e as tramas histórico mundiais. Nas esquinas do desejo, se erguem e se despedaçam horizontes feitos de disputas entre forças das comunidades que imaginamos ou não partilhar. Nos simbólicos que compõem os territórios, existências recaem sobre os sujeitos - como única instância de responsabilidade de si-os fios, as correlações de força, as manhas, fortunas e infortúnios. 
Entretanto, como dar conta da própria história se ela começa a ser escrita e é alvo de embates de tantos tempos e espaços diferentes? Mais do que um lugar valorativo, as narrativas de si permitem "escutar com os olhos" e "ouvir com o coração" os atravessamentos e enfrentamentos constituintes das pessoas, como nos ensina o senso comum: Quem me olha assim, não sabe pelo que passei...

\section{REFERÊNCIAS}

ANDERSON, Benedict. Comunidades Imaginadas. Reflexões sobre a origem e a difusão do nacionalismo. São Paulo: Companhia das Letras, 2008.

ARQUIVO DISTRITAL DO PORTO. Registo de passaportes- Livro 238. Porto, Portugal, 2013. Disponível em: http://pesquisa.adporto.arquivos.pt/viewer?id=411623. Acesso em: jul. 2020.

BENJAMIN, Walter. Obras Escolhidas. Magia e Técnica, Arte e Política. São Paulo: Brasiliense, 1994.

BHABHA, Homi K. O local da cultura. Belo Horizonte: Editora UFMG, 2001.

BRASIL. Ministério da Justiça e Segurança Pública. Sistema de Informações do Arquivo Nacional. Brasília, DF: SINAN, 2020. Disponível em: http://sian.an.gov.br/sianex/ consulta/login.asp. Acesso em: 26 jul. 2020.

BROCOS, Modesto. A Redenção de Cam. 1895. 1 original de arte, óleo sobre tela, 199 x 166 cm. Rio de Janeiro: Museu Nacional de Belas Artes. Disponível em: http:// enciclopedia.itaucultural.org.br/obra3281/a-redencao-de-cam. Acesso em: 26 jul. 2020.

CAMINHA, Pero Vaz de. A Carta de Pero Vaz de Caminha. Petrópolis: Vozes, 2019.

CASTRO, Andreia Alves Monteiro de. Cores, cheiros e sabores - Corpo feminino e literatura no Século XIX. Terceira Margem, Rio de Janeiro, Ano 24, n. 43, p. 90-106, maio/ago. 2020.

CERTEAU, Michel de. A escrita da História. Rio de Janeiro: Forense, 1982.

CHARTIER, Roger. A História Cultural entre práticas e representações. Tradução de Maria Manuela Galhardo. Lisboa: Difusão, 1990.

CORBIN, Alain. Saberes e Odores. São Paulo: Cia. das Letras, 1987.

CRENSHAW, Kimberle. Interseccionalidade na discriminação de raça e gênero, 2012. Disponível em: https://nesp.unb.br/popnegra/images/library/Kimberle-Crenshaw-Inters ecionalidadenadiscriminaoderaaegenero.pdf. Acesso em: 29 ago. 2020. 
DIDI-HUBERMAN, Georges. Sobrevivência dos Vaga-lumes. Belo Horizonte: Editora UFMG, 2011.

ENGEL, Magali Gouveia. Paixão e morte na virada do século. Disponível em: http:// www.observatoriodaimprensa.com.br/marcha-do-tempo/paixao-e-morte-na-virada-doseculo. Acesso em: 29 ago. 2020.

FREYRE, Gilberto. Casa-Grande \& Senzala. São Paulo: Global, 2005.

GANDÂVO, Pero de Magalhães. Tratado da Terra do Brasil: história da província Santa Cruz, a que vulgarmente chamamos Brasil. Brasília: Senado Federal, 2008.

GEORGE, Duby; PERROT, Michelle. Imagens da Mulher. Porto: Edições Afrontamento, 1992.

FANTASIO. Na Exposição II A Redenção de Cham. Gazeta de Noticias, Rio de Janeiro, 5 set. 1895, p. 1. Disponível em: http://www.dezenovevinte.net/egba/index. php?title=FANTASIO._FANTASIO_NA_EXPOSI $\%$ C3\%87\%C3\%83O_II_A_ REDEN\%C3\%87\%C3\%83O_DE_CHAM._Gazeta_de_Noticias\%2C_Rio_de_ Janeiro\%2C_5_set._1895\%2C_p. 1. Acesso em: julho, 2020.

KIENING, Christian. O Sujeito Selvagem. São Paulo: Edusp, 2014.

MATTOS, Maria Hebe. Políticas de reparação e identidade coletiva no meio rural: Antônio Nascimento Fernandes e o quilombo São José. Estudos Históricos, Rio de Janeiro, n. 37, p. 167-189, jan./jun. 2006.

MUNANGA, Kabengele. Rediscutindo a mestiçagem no Brasil: identidade nacional versus identidade negra. Belo Horizonte: Autêntica, 2019.

PERROT, Michele. Os silêncios e o corpo da mulher. In: O corpo feminino em debate. MATOS, Maria Izilda Santos de; SOIHET, Rachel (org.). São Paulo: Editora UNESP 2003. p. 13-27.

PERROT, Michele. Minha história das mulheres. Tradução de Angela M. S. Corrêa. São Paulo: Contexto, 2013.

QUILOMBO SÃO JOSÉ. Foto. Valença, RJ, 19 maio 2013. Facebook: Quilombo São José. Disponível em: https://www.facebook.com/437651249613493/photos /a.570338886344728/570338889678061. Acesso em: 26 jul. 2020.

SANT'ANNA, Affonso Romano de. O canibalismo amoroso. Rio de Janeiro: Rocco, 2011.

TORRES, Gênesis (org.). Baixada Fluminense: a construção de uma história: sociedade, economia, política. Rio de Janeiro: INEPAC, 2008. 


\section{FONTES}

A Batalha, ano II, n. 183, p. 3, 10 abr. 1930.

Correio da Manhã, ano XXX, n. 10875, p. 6, 10 abr. 1930.

Correio da Manhã, ano XXX, n. 1101719, p. 7, nov. 1930.

Crítica, ano II, n. 333, p.1, 11 dez. 1929.

Crítica, ano II, n. 337, p. 2.

Crítica, ano II, n. 346, p.1, 26 dez. 1929.

Diário Carioca, ano III, n. 735, p. 8, nov. 1930.

Diário da Noite, ano XIV, n. 365, p. 8, 26 dez. 1942.

Gazeta de Noticias, Rio de Janeiro, p. 1, 5 set. 1895.

O Cruzeiro, ano XV, n. 34, p. 36, 19 jun. 1943.

O Mequetrefe, ano I, n. 29, p. 1, 15 jul 1875.

Vamos Ler, ano VII, n. 354, capa.

Vida Doméstica, ano XXIV, 01, n. 309, p. 82, 12 dez. 1943.

Texto recebido em 29/08/2020.

Texto aprovado em 08/11/2020. 